Article

\title{
Drawing as a Space for Social-Cognitive Interaction
}

\author{
Vanessa De Andrade 1,*, Sofia Freire ${ }^{1}$ (D), Mónica Baptista ${ }^{1}$ (D) and Yael Shwartz ${ }^{2}$ (D) \\ 1 Institute of Education, University of Lisbon, 1649-013 Lisbon, Portugal; asraposo@ie.ulisboa.pt (S.F.); \\ mbaptista@ie.ulisboa.pt (M.B.) \\ 2 Department of Science Teaching, Weizmann Institute of Science, Rehovot 7610001, Israel; \\ Yael.shwartz@weizmann.ac.il \\ * Correspondence: vanessafigueiredo@campus.ul.pt
}

Citation: Andrade, V.D.; Freire, S.; Baptista, M.; Shwartz, Y. Drawing

as a Space for Social-Cognitive

Interaction. Educ. Sci. 2022, 12, 45.

https://doi.org/10.3390/

educsci12010045

Academic Editor: James Albright

Received: 15 November 2021

Accepted: 8 January 2022

Published: 13 January 2022

Publisher's Note: MDPI stays neutral with regard to jurisdictional claims in published maps and institutional affiliations.

Copyright: (c) 2022 by the authors. Licensee MDPI, Basel, Switzerland. This article is an open access article distributed under the terms and conditions of the Creative Commons Attribution (CC BY) license (https:// creativecommons.org/licenses/by/ $4.0 /)$.

\begin{abstract}
Drawing is recognized as a powerful tool to learn science. Although current research has enriched our understanding of the potential of learning through drawing, scarce attention has been given to the social-cognitive interactions that occur when students jointly create drawings to understand and explain phenomena in science. This article is based on the distributed and embodied cognition theories and it adopted the notion of we-space, defined as a complex social-cognitive space, dynamically established and managed during the ongoing interactions of the individuals, when they manipulate and exploit a shared space. The goal of the study was to explore the role that collaborative drawing plays in shaping the social-cognitive interaction among students. We examine this by a fine-grain multimodal analysis of a pair of middle school students, who jointly attempted to understand and explain a chemical phenomenon by creating drawings and thinking with them. Our findings suggest that collaborative drawing played a key role in (i) establishing a genuine shared-action space, a we-space, and that within this we-space it had two major functions: (ii) enabling collective thinking-in-action and (iii) simplifying communication. We argue that drawing, as a joint activity, has a potential for learning, not restricted to the cognitive process related to the activity of creating external visual representations on paper; instead, the benefits of drawing lie in action in space. Creating these representations is more than a process of externalization of thought: it is part of a process of collective thinking-in-action.
\end{abstract}

Keywords: collaborative drawing; student-created drawing; social-cognitive interaction; distributed cognition; multimodality; science education

\section{Introduction}

The importance of drawing for the scientific practice [1] and the growing recognition of drawing as a powerful tool to learn science [2-4] have recently inspired a number of studies in science education as well as in different content domains and learning-teaching environments. Drawing facilitates conceptual change and the development of more complex mental models [5-7] as it enhances students' visualization of ideas and concepts during the exploration of scientific models [8,9]. It also enables students to process ideas, move toward higher levels of thinking, understand more complex topics, and develop more complex explanations $[6,10]$. Importantly, when students create their own drawings, they become highly engaged with learning [2,11]. Thus, having students creating their own drawings is typically associated with a better understanding than when students learn from visual representations they have been given $[3,12]$. In particular, collaboratively created drawings provide opportunities for students to integrate multiple representations, exchange and clarify ideas, engage in elaborative discussion, build on each other's ideas, and establish shared representation and deeper science understandings $[6,10,11,13,14]$. Thus, collaborative drawings have affordances that emerge from both visual representation and the collaborative discourse around drawings' creation. In creating their drawings, students 
have the opportunity to discuss and to externalize their ideas in a shared material space, which facilitates following a line of thinking $[10,15]$.

Although current studies have enriched our understanding of the potential of learning through drawing, questions remain open about the social-cognitive interaction that occurs around drawings' creation [7]. It is still unclear, for example, how drawing facilitates social-cognitive interaction between students, or how drawing shapes the products of that collaboration. In fact, studies on drawing have mainly focused on the effects of drawing on students' learning. These perspectives tend to conceptualize drawing as a tool that serves processes, such as to help students construct appropriate mental models or communicate the end product of their work [7]. While these studies consider the importance of the social dimension of the practice of drawing, with few exceptions they do not make social interaction an integral part of the analysis of the role of drawing for learning. From science education to other fields of research in education, only a scarce number of studies on learning through drawings' creation have conceptualized drawing as a situated activity, that is, an activity that derives its meaning from the environment where it is created and used, and, as such, an activity with the potential to shape the environment of its creation and use $[16,17]$. However, this perspective is essential to expand our understanding of the mechanisms by which drawing may drive learning, as it allows us to capture the features of the social and cognitive interactions with the drawing activity.

In this article, we take the theoretical perspective of distributed and embodied cognition. Theories of distributed cognition postulate that "cultural and cognitive processes are not merely interrelated but are co-implicated" [18] (p. 83), i.e., they are shared processes [19]. Distributed cognition assumes that all instances of cognition emerge from distributed processes and are not necessarily centralized in the mind or its representational processes $[18,19]$. Thus, cognitive processes cannot be treated separately from the environment in which they occur but as emergent from the interactions among individuals and the environment, including its social-cultural features [20-22]. Embracing this view implies that two (or more) individuals jointly working on a task are conceptualized as a cognitive system, and, as such, any cognitive achievements in such system emerge from the complex interaction among them and the properties of the environment $[18,23]$.

Embodied cognition theories focus on the roles of perception and action in cognition $[24,25]$. Theories on embodied cognition argue that cognitive processes cannot be divorced from the environment where they take place, and from the states of the body and the interactions between the body and the environment. Evidence supporting the embodied cognition approach has grown in recent years and generally supports the idea that perception and action influence cognition [26-29]. In particular, a variety of studies focus on gestures as embodied actions in the environment [17,28,30-32]. Gestures (hand movements) are themselves one kind of embodied expressions, which not only reflect an internal representation but also influence it, at least in part, by embodying cognition in action [28].

The perspective of embodied cognition is important within the perspective of distributed cognition, when the focus is on a system involving the interaction of individuals with each other and with the material environment around them. In these complex systems, the interaction of distributed and embodied cognition is substantial. Cognitive processes are distributed among interactions between individuals' minds, the environment, and the individuals' embodied actions in the environment $[20,21,26]$. By adopting the perspectives of distributed and embodied cognition, we are assuming that cognition is typically distributed in multiple ways, including embodied actions in the environment. Thus cognitive processes encompasses both internal and external processes, and uses the environment and actions on the environment as external informational structures that complement internal representations $[24,25,33]$. All together, these elements form an integrated cognitive unit, whose properties go beyond the simple aggregation of the cognitive properties of any of the individuals that are part of the system [20,23]. Besides the cognitive effects of distributed systems, some authors have also noted their social effects. Indeed, while socially 
interacting, individuals manipulate their surrounding environment creating a complex dynamic system in which each individual's actions shape each other's actions in a dynamic process of mutual-coordinated interactions. In distributed and embodied systems, social and cognitive processes interact and shape each other [34-36].

In sum, this study assumes that students involved in collaborative drawing activities form a distributed socio-cognitive system, comprising the students, the drawings that they created, and their communicative and embodied actions on the drawing. From these perspectives, the goal of the current study was to explore the role that collaborative drawing plays in shaping the social-cognitive interaction among students. For examining the social-cognitive interactions around drawing, we borrowed from Krueger [34] the concept of we-space, defined as a complex social-cognitive space, dynamically established and managed during the ongoing interactions of the individuals, when they manipulate and exploit their shared space. For that, this paper presents a pair of middle school students who jointly attempted to understand and explain a chemical phenomenon by creating drawings and thinking with them.

\section{Methods}

\subsection{Setting and Context}

The current study is a detailed case study focusing on the observation of one pair of 8th grade students, aged 14-15, Iris and Raul (pseudonyms), who jointly created drawings while they were trying to understand and explain a chemical phenomenon. Participants attended a three-day workshop about chemical change led by two authors of this study. The sessions were carefully designed to afford opportunities for student discovery through collaboration. The broad aim of the research was to investigate how pairs of students collaborate and reason about the mechanisms underlying a chemical reaction through drawing creation. The phenomenon under explanation was the reaction of an antacid (i.e., pills of calcium and magnesium carbonate) to neutralize the stomach's acidity (hydrochloric acid).

Data were drawn from the first session of this workshop, where Iris and Raul worked together to create a drawing at the level of particles (i.e., the atoms, molecules, etc.) In this case, it concerns the chemical reaction of calcium and magnesium carbonate (the main components of the antacid pills) and hydrochloric acid (the main component contributing to the acidity of gastric juice). In creating the drawing, students were asked to imagine that they could see the smaller parts that make up matter constituent of the acid juices of the stomach and the antacid pills and to draw what they would see happening along the reaction. To assist in creating their drawings, students were provided with a schematic template with three frames, each corresponding to a stage of the reaction: before, during, and after.

The goal of providing students with a template focused on different stages of the process was to extend drawings from space to time, stimulating students to represent temporal events depicted in the moments before, during, and after [37]. This decision was consistent with the workshop's goal: to prompt students' thinking about the underlying mechanisms that give rise to the target phenomenon. As we aimed to stimulate interactions for capturing the students' way of thinking and interacting with each other and the drawing, we provided the minimum amount of information regarding the creation of the drawing. For instance, no information was provided about the structure of the chemical identities participating in the reaction. By doing this, students had to jointly decide which elements to represent in their drawings and how to visually represent them in space and through time. In this way, we may consider that the task is a rather open task. During the session, the students were assisted by the two researchers who led the workshop, who only intervened to structure the session (for instance, to introduce information needed to perform the tasks) and to make any clarifications when needed. The decision to reduce researchers' interventions to a minimum was thought to let students work in pairs so that they could engage in an easygoing conversation with minimum intervention and constrains. 


\subsection{Data Collection and Analysis}

The pair's interaction during the session was video-recorded, and the artifacts they produced were collected and digitalized. The analytical practice adopted in this study was fine-grained analysis inspired by the multimodal-grounded approach [38,39]. The multimodal system of analysis in this study was the drawing and participants' interactions with each other and with the drawing. The primary modalities analyzed in this study included talk and actions performed on the drawings, including sketching, gesture, and gaze. The first author conducted the multimodal transcription of the video-recorded. The multimodal approach used in transcription [39] integrate verbatim transcription of talk, snapshots of the video, description of every action performed on the drawings that included sketching, gesture, and gaze, and when applied, an interpretative description of the interaction with the propose to contextualize a particular event in the interaction. Table 1 presents and describes the primary modes of interaction that emerged from the analysis of the interaction, as well as the transcription conventions used to illustrate these modes of interaction, based on Wardak [18].

Table 1. Description of the modes analyzed, codes for gestures, and transcription conventions used.

\begin{tabular}{|c|c|c|c|}
\hline Mode & Description & & inscription Conventions \\
\hline \multirow{6}{*}{ Talk } & \multirow{6}{*}{ Students' utterances in the interaction. } & {[} & $\begin{array}{l}\text { A point where the two participants } \\
\text { start talking simultaneously. }\end{array}$ \\
\hline & & $=$ & $\begin{array}{l}\text { A latched utterances, with no } \\
\text { perceptible gap. }\end{array}$ \\
\hline & & (.) & Short pause. \\
\hline & & $(2)$ & Pause in seconds. \\
\hline & & $\ldots$ & A utterance trailing off. \\
\hline & & : & Lengthened syllables. \\
\hline \multirow{3}{*}{ Drawing } & \multirow{3}{*}{$\begin{array}{l}\text { Students sketch or make any kind of marks on the drawing, such } \\
\text { as adding or deleting an element or highlighting some particular } \\
\text { aspect or feature. }\end{array}$} & $(\ldots)$ & $\begin{array}{l}\text { Some material of the original } \\
\text { transcript that has been omitted as } \\
\text { it is not perceptible. }\end{array}$ \\
\hline & & @text@ & Participant drawing. \\
\hline & & \#_text_\# & $\begin{array}{l}\text { Participant adding a mark or an } \\
\text { inscription to the drawing. }\end{array}$ \\
\hline Gaze & Students looked at the drawing for a moment. & ${ }^{\wedge} \underline{\text { text }}^{\wedge}$ & Participant looking at the drawing. \\
\hline \multirow[t]{2}{*}{ Gestures } & \multirow{2}{*}{$\begin{array}{l}\text { Students moved their hands to point to any element or part of the } \\
\text { drawing and/or to interact with the drawings in some way, such } \\
\text { as to animate an element of the drawing, to depict some property } \\
\text { of an element, or to simulate some action or behavior. }\end{array}$} & $\{\underline{\text { text }}\}$ & $\begin{array}{l}\text { Participant gesturing on the } \\
\text { drawing. }\end{array}$ \\
\hline & & *text* & $\begin{array}{l}\text { Other non-verbal actions (e.g., } \\
\text { reading the information in the } \\
\text { pills' box). }\end{array}$ \\
\hline
\end{tabular}

The multimodal analysis and transcription followed an iterative process. First, to complete the transcription, the video records were re-watched, and any observed action performed on and with the drawing was highlighted in the transcription using the set of conventions displayed above. Second, a description of the actions performed on the drawing was added in a separate column. Third, a preliminary narrative was constructed around the theme of drawing and the social-cognitive interactions. In this phase, particular attention was given to how students interacted with the drawings and how these interactions drove and shaped their social and cognitive processes. In this process, critical incidents indicative of the role and function of drawing in shaping the social-cognitive interaction among students were further examined. In the following section, we present our findings and discussion. 


\section{Findings and Discussion}

Through a fine-grained multimodal analysis of students' creating and using a drawing to understand and explain a chemical phenomenon, we identified three key themes related to the ways in which drawing works as a space for social and cognitive work: (i) establishing a we-space; (ii) enabling collective thinking-in-action, and (iii) simplifying communication.

\subsection{Establishing a We-Space}

The strip of interaction that follows occurred when Iris and Raul started to explore how the chemical reaction under explanation occurred and to consider how to represent what was happening at the level of particles:

\begin{tabular}{|c|c|c|c|c|}
\hline Line & Talk & $\begin{array}{l}\text { Actions Performed } \\
\text { on Drawing }\end{array}$ & Snapshot of the Video & $\begin{array}{l}\text { Description of the } \\
\text { Visual Frame }\end{array}$ \\
\hline
\end{tabular}

Raul: Well,

$\left\{\right.$ we have to draw a molecule ${ }^{[1]}$

and then another molecule

2 coming and hitting ${ }^{[2]}$ and doing new things $\left.{ }^{[3]}\right\}$ (4) And now::

(2) [What are they? ${ }^{[4]}$ I don't know.
Gaze: Iris and Raul look at the empty drawing-sheet.

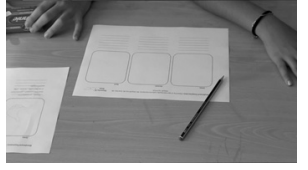

Raul and Iris are siting side by side with the drawing-sheet in front of them.
Gestures: ${ }^{[1]}$ Points towards the before-reaction frame; ${ }^{2]}$ points towards the during-reaction frame; [3] and points to the after-reaction frame.
Raul and Iris are sitting side by side with the drawing-sheet in front of them Raul gestures over the drawing-sheet and Iris listen and follows Raul's actions.

Iris and Raul were in front of the drawing-sheet, where they were supposed to draw the three stages of the chemical change (before-during-after) (see snapshot in line 1), when Raul initiated the conversation by describing what would be happening in each temporal frame [line 2]. He expressed himself using words synchronized with explicit pointing gestures towards each temporal frame on the drawing-sheet. While his words conveyed the entities and the action in which entities engaged, his gestures conveyed the temporal sequence of these actions. Together, Raul's words and embodied actions on the drawing-sheet worked to enact a representation of how the chemical reaction under explanation occurs. Being enacted in words and embodied action in the drawing, Raul's representation formed part of the material space that he and Iris shared, and it became perceptually accessible, enabling a direct experience for both. Indeed, Iris was able to derive meaning from Raul's enacted representation on the drawing-sheet, as her following action showed. Her response overlapped with Raul's concluding words. When he queried about the identity of the "molecules" participating in the reaction ("What are they? I don't know."), Iris answered that she knew the composition of one of these "molecules" ("The hydrochloric acid I know what it is") [line 3]. In her immediate reaction to Raul, Iris signaled her understanding of Raul's idea, as well as her intention to follow Raul's thinking.

Hence, even before students had started to draw things on the paper, the drawing (or the drawing-sheet) had already become part of the material environment that both students shared; it played an important role in establishing their we-space-a social space of joint attention and mutually-coordinated interactions-as it functioned as a stable material medium for interaction that students manipulated to create a representation and to convey it in a perceptible way. The direct experience (by listening, seeing, and pointing) along with the enacted representation conveyed extensive information about each individual representation [24], essential to facilitate interpersonal understating and mutual engagement [11,40,41]. 
In addition, Raul's actions exploiting the drawing-sheet may have shaped the representation he created. Raul's spontaneous actions on the temporal frames of the drawing-sheet coordinated with talk may have not merely worked to convey a fully internal-formed representation; these actions may have also become part of the material process of thinkingin-action (as proposed by Krueger [42]), thus shaping the representation he created. According to models on distributed and embodied cognition, interacting with the material environment shapes one's cognitive activity, and, likely, any representation emerging from this process will have features of the environment in which it was created [21,24,27].

Following this initial intervention, the two students began to be concerned about the entities participating in the reaction ("molecules") and how to represent them visually in the drawing. The next piece of interaction illustrates this negotiation.

\begin{tabular}{|c|c|c|c|c|}
\hline Line & Talk & $\begin{array}{l}\text { Actions Performed } \\
\text { on Drawing }\end{array}$ & Snapshot of the Video & $\begin{array}{c}\text { Description of the } \\
\text { Visual Frame }\end{array}$ \\
\hline
\end{tabular}

3 Iris: [The hydrochloric acid, I know what it is $($.

Raul: Okay. First: What is this? *it's calcium carbonate $^{*}$ (5) How do we draw this? Carbonate: C, Calcium: $\mathrm{Cl}$ ? (4)

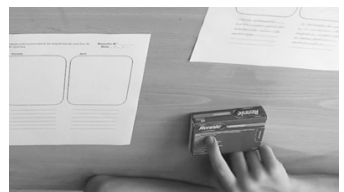

Raul Picks-up the antacid pills' packaging and starts reading the name of components in it, i.e., the calcium carbonate and magnesium carbonate.

Iris: But, I don't remember the color of the little balls!?

6

Raul: The little balls?! The little balls?! (.) But, it doesn't matter=

Iris: $=$ No::: the $[\{$ representation:

7 the drawing:: $\}^{[1]}$ like imagine the oxygen, \{the oxygen is ... $\}^{[2]}$.
Gesture: ${ }^{[1]}$ Taps the drawing-sheet in before-reaction frame with the pencil.

${ }^{\text {[2] }}$ Repeats the same gesture.

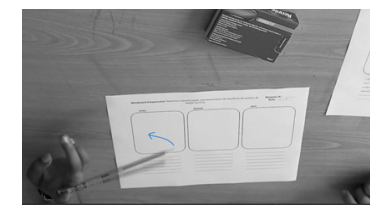

\section{Raul: [The little balls?}

You draw a little ball with another one next to it and you put the two

8 together, and that's a molecule.

Calcium carbonate ... ${ }^{*}$ How do we draw calcium carbonate ${ }_{-}^{* 1}(5)$ It's C, that's the carbon [and $\mathrm{Cl}$, that's the calcium. $\mathrm{C}$ and $\mathrm{Cl}$ or $[\mathrm{Cl}$ and $\mathrm{C}$.

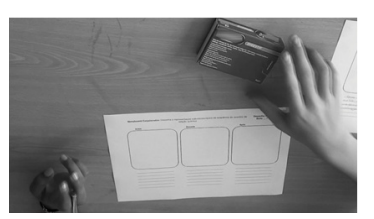

Raul picks up the antacid pills' packaging and puts it down again.

9 Iris:

[It's carbonate.

[and calcium is $\mathrm{Ca}$, isn't it?

Raul: Okay, it's C with Ca (... )

Okay, we draw=

Iris: =Well, but inside what is it?\{Like a circle with (1) ${ }^{[1]}$
Gestures: ${ }^{[1]}$ Gestures a circle over the surface of the paper. with the pencil.

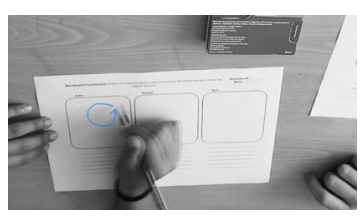


12

Raul: We draw the $\mathrm{C}$, with the $\mathrm{Ca}$

next to $\mathrm{C}=$
Raul: @_(5) Ok. It might be like this @ ${ }^{[1]}$ (.) @_It must be bigger (8) @ [2].
Drawing: [1] Takes the pencil from Iris and draws a circle divided in two parts, and then

[2] deletes it and draws a new one, but bigger; starts to inscribe $\mathrm{Ca}$ in one of the parts.

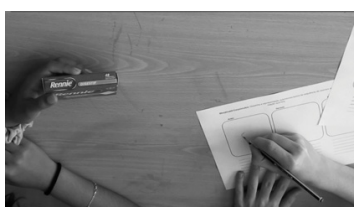

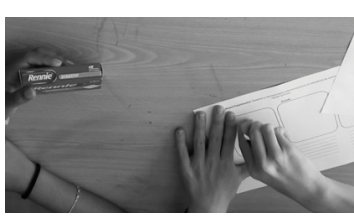

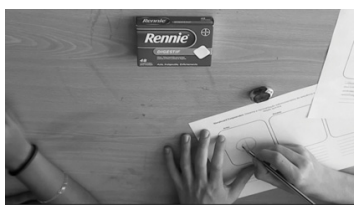

Raul starts to draw a circle, but then decides that it is too small, so he deletes it and draws a bigger one.
Iris: But not

15 \{here. There is none of this, yet. But only $\mathrm{H}-\mathrm{Cl}$.
Gesture: Points towards the drawing and then to the antacid pills' box.

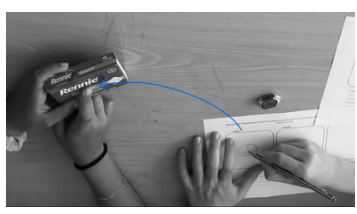

Iris showing Raul that in the frame before-reaction the entities of the antacid pills were not to be drawn yet, because in the beginning it is only the acid. continues explaining to
As Raul deletes the entity "C-Ca" Iris Raul why it should only be the acid in the frame before-reaction.

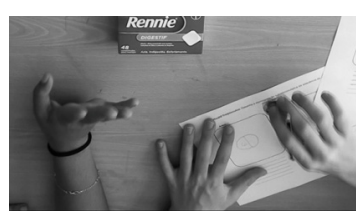

Drawing: Picks the rubber

"C-CA" he have drawn in A13.

\section{Raul:}

@_Okay. So it's H:: with Cl::_@[1]. Okay:: it's\{here. [Here it's the $\mathrm{H}$ and the $\mathrm{Cl}\}^{[2]}$
Drawing: ${ }^{[1]}$ Draws the entity "H-Cl".

Gesture: ${ }^{[2]}$ Points towards the "H" and then the "Cl".

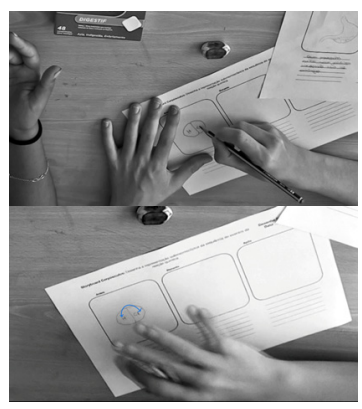


From the above excerpt, it soon became apparent that each student had different representations of the entity "molecule". Raul's intended representation was a symbolic representation (an entity represented by its chemical symbol), while Iris's intended representation was a pictorial representation (circles with different colors that stands up for each chemical entity). As these entities are key agents in the mechanism they were attempting to explain, establishing a representational visual convention meaningful for both is an essential step.

Nevertheless, the initial exchanges in [lines 3-7] show signs of personal disengagement from the interaction. Raul acts as he was having a conversation with himself, and in line 4 , he seems to ignore Iris's intervention. Actually, Raul's reaction was a response to his own queries and an elaboration of his own ideas. Further ahead, in line 6, Raul reacted with disapproval to Iris's wonderings about the color for representing the entities of the acid molecule [line 5]. Importantly, if these signs of social disengagement had not had been repaired, they could have ended up compromising the genuine mutual-cooperation necessary for establishing and sustaining a we-space. However, Iris, apparently perceiving Raul's disengagement and willing to make her own intentions understood, reacted by elaborating her viewpoint. In line 7, she tapped in the first frame of the drawing-sheet, while saying: "the representation: the drawing", and as she continued: "like imagine the oxygen, the oxygen is ..." ", she repeated her gesture as she wanted to signal something meaningful to her. Iris's words coordinated with embodied actions on the drawing-sheet worked to reveal relevant important information about her current cognitive status (her concerns about how to actually draw a visual representation of the target entities). These actions may have also shaped Raul's following move, as after Iris's intervention he tried to meet her concerns by providing an eloquent oral description for the spatial arrangement of "the little balls" (suggested by Iris) in order to visually represent a "molecule" [line 8]. Indeed, Raul's move showed signs of cooperation and attention to create an interpersonal understanding of the situation. Thus Iris's gestures on the drawing-sheet seemed to work as a perceptual stimulus for monopolizing joint attention in managing the we-space.

However, Raul's verbal description did not seem clear enough for Iris, as she remained somewhat confused about what to draw ("Well, but what is inside?") [line 11]. So, she said "Like a circle" while gesturing a circle over the drawings-sheet, and afterwards, she pointed to the inside of "it" while saying: "with" - her gestural drawing on the drawing-sheet called Raul's attention to the salient features of her intended representation. He responded by providing further information about how to display the elements in the drawing ("We draw the C, with the Ca next to C") [line 12], although Iris remained somewhat uncertain [line 13]. Raul then decided to pick-up the pencil and draw a possible representation of the target entity. He said: "Ok. It might be like this" as he drew two circles together and inscribed in each one the correspondent chemical symbol [line 14]. In doing so, he transformed an individual/intended representation into a material representation that depicted relevant visuo-spatial features and that became permanently available in the we-space, thus allowing for intersubjective inspection [42]. Readily, Iris pointed to the drawn entity to make her evaluation. Although she agreed with what Raul drew, she noticed that before the reaction, the entities of the antacid pills "were not there [in the stomach]" "but only the $\mathrm{H}-\mathrm{Cl}$ [(the acid) is in the stomach]" [lines 15-17]. This seemed to have made sense to Raul, as he readily changed the representation, accordingly [line 18].

In this case, until Raul drew the entity under discussion, the two students seemed to experience difficulty in making sense of each other's individual/intended representations. In the absence of a material visual representation, they lacked a visual perception of each other's intended representations. Hence, they had to infer each other's representations, which indeed did not occur without misunderstanding. With the representation of the entity under discussion materialized on the paper, evaluating and negotiating its features became a much easier task, facilitating achieving interpersonal understanding about what to draw and how to draw. 
In brief, the drawing (or the drawings-sheet) worked as a material medium in the space shared by both students that they used to enact their actions and that worked to establish a space of joint attention and mutual-coordination, a we-space. Raul outlined a representation that laid the ground for their subsequent activity by performing a sequence of embodied actions on the drawing. When signs of disagreement came about, compromising the wespace, Iris made use of gestures on the drawing-sheet that functioned to manage and keep the joint attention necessary for sustaining the we-space. Finally, the two students ended up establishing a conventionalization to represent the key entities participating in the reaction under explanation. The representation that emerged included aspects of their individuals representations aligned and transformed into a new representation that was the product of their joint attention and mutual coordination, dynamically established in their ongoing interactions around the drawing.

\subsection{Enabling Collective Thinking-in-Action within the We-Space}

The strip of interaction in the following excerpt occurred when the two students were dedicated to draw the during-reaction stage. They had already drawn the entities of the substances they identified during-reaction stage (i.e., the two components of the antacid pills ("C-Ca"; "C-Mg") and the acid ( $\mathrm{H}-\mathrm{Cl})$ ). As they finished, Raul started gesturing over the drawn entities to show them colliding while saying "they collide" [line 29].

\begin{tabular}{|c|c|c|}
\hline Line & Talk & Actions Performed on Drawing \\
\hline 29 & $\begin{array}{l}\text { Raul: So, @ } \\
\underbrace{\text { They collide with each other }^{[2]}}_{\text {It's the C with magnesium, }^{(3)} \mathrm{Mg}}{ }^{[1]}\end{array}$ & $\begin{array}{l}\text { Drawing: [1] Draws the entity "C-Mg" } \\
\text { in the during-reaction frame. } \\
\text { Gesture: }{ }^{[2]} \text { Moves his hand, holding } \\
\text { the pencil, over the during-reaction } \\
\text { frame, making a circle that passes } \\
\text { over the entities represented there } \\
\text { ("C-Mg", "H-Cl", and "C-Ca"). }\end{array}$ \\
\hline
\end{tabular}

Gesture: ${ }^{[1]}$ Positioning she hand over the molecule of acid " $\mathrm{H}-\mathrm{Cl}^{\prime}$ " in the

Iris: And $\left\{\right.$ this one ${ }^{[1]}$ shrinks $\left.{ }^{[2]}\right\}$. during-reaction frame;Gesture: ${ }^{[2]}$ Gestures "shrink" by closing her hand.

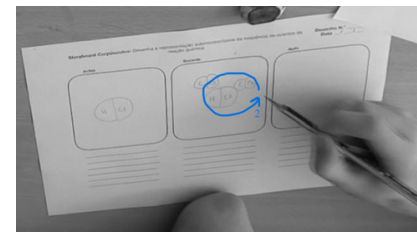

\section{Snapshot of the Video}

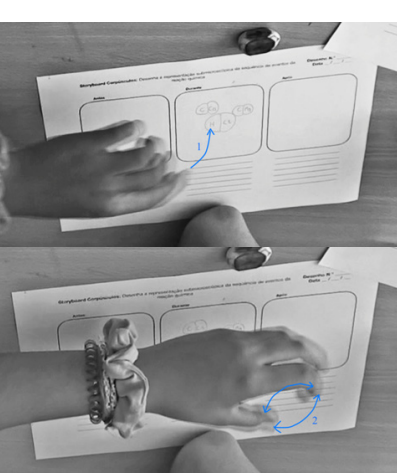

Raul: No, I don't think they shrink (3) they originate new things. (2) @_It's water, It's H-2-O@.
Drawing: Starts drawing the entity "H-O-H" in the after-reaction frame.

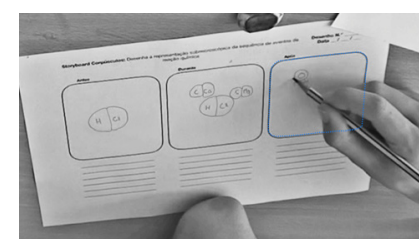

Iris: 
Raul's enacted collision caught Iris's attention, and she immediately reacted by gesturing over the same part of the drawing, the acid molecule shrinking [line 30], while she said: "And, this one shrinks" [line 30]. Iris's gesture was like a continuation of Raul's gestures. Thus, Iris and Raul performed an integrated sequence of gestures during this interaction, building on each other's embodied action on the drawing and generating a visual representation within the we-space. Raul used embodied action to convey the idea of entities colliding. Building on Raul's gestures, Iris then used a gesture for enacting the result of such collision on the acid molecules. The jointly enacted visual representation (of entities colliding and causing the acid molecules to shrink) achieved momentary visibility and significance that otherwise would have not achieved and gained particular interactional relevance. In this way, through a direct visual perception related to the representation activated by the embodied action on the drawing, an understanding of each other's ideas emerged. Indeed, it turned out that Raul became aware that the representation (acid molecule shrinking due to collisions) conflicted with the representation that he had in mind. Apparently, according to Raul's representation of the chemical reaction, molecules collide to originate new ones, i.e., new entities with a different chemical entity, which, in this case, would be the water molecules. However, Iris proposed that collisions cause a change in the molecule's material properties (i.e., size) while maintaining the same chemical identity. Aware of the emergence of different understandings, he proceeded by saying: "I don't think it shrinks. They originate new things", and then he drew a molecule of water in the after-reaction frame (represented as "H-O-H") as he stressed his idea ("It's water. It's $\mathrm{H}-2-\mathrm{O}^{\prime \prime}$ ) [line 31]. Having this entity now available on the drawing, Iris leaned over the drawing, as though she was trying to make sense of something ("look, this is ... "); and after $8 \mathrm{~s}$ of quietly observing the drawing, she came out to make sense of what Raul was proposing: "Ah! So, I see!" and "So, it also originates a salt" [line 32]. The entity drew by Raul was perceived at that moment in a particular way; it gained intelligibility within the activity at hand. In this way, Iris developed a situational understanding of something that she had likely learned as a rule (an acid and an antacid react to originate salt and water).

This example shows that drawing worked as a material shared medium within the wespace that helped students explore each other's ideas in the process of coordinating actions and meanings. With the entities of interest drawn on a shared medium, both students gained direct access to them and were able to manipulate them through embodied actions. Instead of relying on internal representations of these entities, students worked with stable visuo-spatial representations and animated them in real-time by coordinated gestures. Raul enacted the drawn entities' actions in an integrated sequence of gestures while Iris enacted their effects. Thus, from their coordinated actions, an animated representation emerged. Importantly, this representation did not exist until it was enacted in real-time within the we-space. It emerged in a distributed system where each student's individual representation, drawing, and embodied actions on the drawing constitute parts of the material process of thinking-in-action [23,33] - in turn, providing an animated representation within the we-space allowed for further thought and collaboration, which enabled students to evaluate their individual representations and change them via thinking-in-action. What is most interesting to consider in this example is that drawing can be conceptualized as more than a visuo-spatial representation of thought on paper. Instead, creating and interacting with a drawing is part of the dynamic process of collective thinking-in-action. Drawing invites students into the interactive engagement and coordination of meanings that emerge from this interactive process; these meanings will eventually change and evolve by students coordinately acting upon the drawing with talk and gestures.

\subsection{Simplifying Communication}

As the two students advanced in the task, their talk became more specified and conceptualized by gestures on the drawings. The strip of interaction in the following excerpt shows how students' talk was combined with highly active pointing work on the drawing that worked to simplify the flow of the conversation. 


\begin{tabular}{|c|c|c|c|}
\hline Line & Talk & Actions Performed on Drawing & Snapshot of the Video \\
\hline 40 & $\begin{array}{l}\text { Iris: I don't know, but I think it's } \\
\text { something like } \\
\text { \{these three will combine somehow } \\
\text { to originate things (...) So ... }\end{array}$ & $\begin{array}{l}\text { Gesture: Gestures a circle with her finger } \\
\text { over the entities: "C-Ca", "Mg-C" and } \\
\text { " } \mathrm{H}-\mathrm{Cl}^{\prime} \text { in the during-reaction frame. }\end{array}$ & \\
\hline
\end{tabular}

Raul: We should focus on just one. ^(5) Ah! No::^[1] We have to do\{this one ${ }^{[2]}$ with this ${ }^{[3]}$ and this one ${ }^{[4]}$ with this one $\left.{ }^{[5]}\right\}$.
Gaze: ${ }^{[1]}$ Looking at the drawing.

Gesture: ${ }^{2]}$ Puts his finger over the entity "C-Ca"; then

[3] over the entity " $\mathrm{H}-\mathrm{Cl}^{\text {"; }}$ and then ${ }^{[4]}$ he puts his finger over the entity " $\mathrm{C}-\mathrm{Mg}^{\prime}$ "; and then ${ }^{[5]}$ again over the entity " $\mathrm{H}-\mathrm{Cl}^{\prime}$.

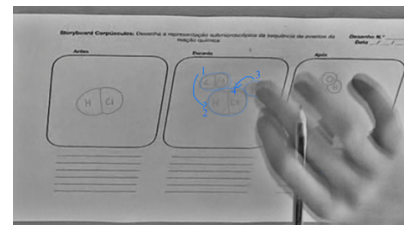

42 Iris: Yeah!

Raul: There are two different combinations. (8) What is the name of the tablets? (2) Rennie, isn't it? (2) @ Rennie are these two together @ ${ }^{[1]}$ $\overline{\text { And then, }\left\{\text { originates water }{ }^{[2]}\right.}$ (.) and the other...

Iris: I think \{these two together\} [1] originate the calcium chloride; and \{these two ${ }^{[2]}$ originate the magnesium chloride. But \{all three, I don't know ${ }^{[3]}$.
Drawing: ${ }^{[1]}$ Draws an arrow connecting the entities "C-Ca" with the "C-Mg" and writes "Rennie".

Gesture: ${ }^{2]}$ Points with the pencil to the entity "H-O-H" drawn in the after-reaction frame.

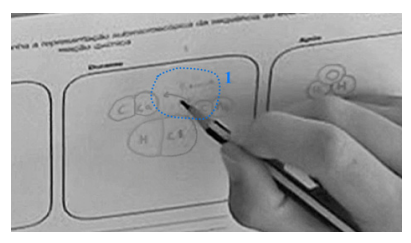

Gesture: ${ }^{[1]}$ Puts her finger over entity " $\mathrm{Cl}^{\prime}$ and then over the entity " $\mathrm{Mg}$ ".

[2] Repeats the same gesture with the entities " $\mathrm{Cl}^{\prime}$ and "Ca".

[3] Gestures a circle with her finger over the entities: "C-Ca"; "Mg-C"; "H-Cl" (the gesture is similar to A38).

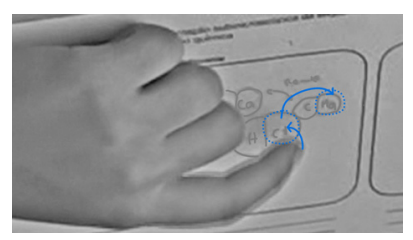

Raul: We (...)

$45 \quad$ this ${ }^{[1]}$ and this ${ }^{[2]}$, and this ${ }^{[3]}$ with this ${ }^{[5]} \ldots$...
D-Gestures: ${ }^{[1]}$ Points towards the entity " $\mathrm{H}-\mathrm{Cl}^{\prime}$; and then ${ }^{[2]}$ towards the "C-Ca"; and again ${ }^{[3]}$ towards " $\mathrm{H}-\mathrm{Cl}^{\text {" and }}{ }^{[4]}$ then "C-Mg" (the gesture is similar to A39).

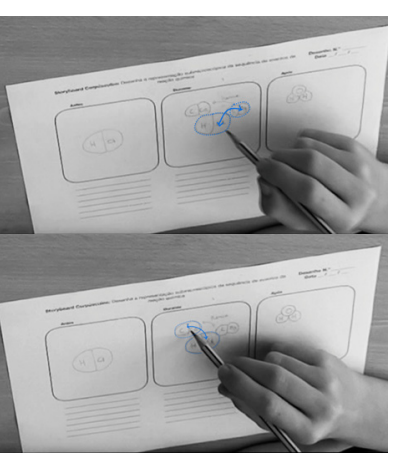

46 Iris: But what? The two?

47 Raul: It originates two. (8) It's the ^(5)^No!?

Gaze: Stares at the drawing.

Iris: ^Does it originate one or two salts?^

[1] Will it be \{this with this and this with this ${ }^{[2]}$; or these three

together? $\left.{ }^{[3]}\right\}(\ldots)$

Gaze: ${ }^{[1]}$ Keeps looking at the drawing; Gesture: ${ }^{[2]}$ Points to " $\mathrm{Mg}^{\prime \prime}$ and then to "Cl», and then again to " $\mathrm{Ca}$ " and to " $\mathrm{Cl}^{\prime}$ (gestures similar to A42);

${ }^{[3]}$ with her finger circles the three entities: "Cl", "Ca" and "Mg" (the gesture is similar to A38). 
Raul: It is this one with this one [1] and this one with this one $\left.{ }^{[2]}\right\}$. the same tablet, because perhaps one is stronger than the other, or it might be that they somehow complement each other.

Gesture: ${ }^{[1]}$ Points towards " $\mathrm{H}-\mathrm{Cl}^{\prime \prime}$ and then towards "C-Ca";

[2] and again [2] points towards " $\mathrm{H}-\mathrm{Cl}^{\text {" }}$ and then towards " $\mathrm{C}-\mathrm{Mg}^{\prime}$ " (the gesture is similar to A39).

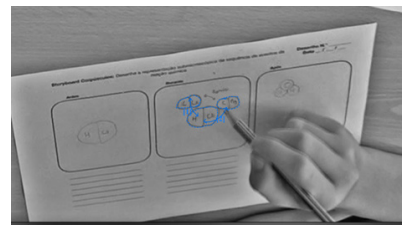

To an outside observer, these conversational turns look fragmented and sometimes hard to follow; this reveals that Iris and Raul have created a we-space that it is genuinely their own space, where they successfully function and communicate. Their talk included many deictic expressions such as "this one", "there", "with", which only have meaning when considered in coordination with the gestures performed on the drawing. The entities of interest were referred to by pointing coordinated with deictic expressions, such as "this one" or "these two"-lines A41, A42, and A44 display some examples. The students avoided cumbersome scientific names by pointing to the entity of interest and by simply saying "this one" or "these two". Without being overburdened by scientific terms, students were able to keep the conversation on task with minimum effort. Here, their pointing gestures to the entities also worked to suggest the possible rearrangements that entities undergo during the reaction. They indicated how entities, during a reaction, rearrange by a series of sequential pointing gestures on the entities of interest. For example, when saying "this one", they pointed to one of the entities of interest. While saying "with", they moved their finger to indicate the other [line 44]. On another occasion, they put one finger over an entity and the other finger over another while saying "these two together".

Adding an element to the drawings was also used to highlight some aspect referred to in talk and to hold it, as in line 43, when Raul drew an arrow grouping the two entities of the antacid pill and wrote the commercial name of the antacid pills over it while saying "Rennie is these two together". In doing so, he emphasized the idea that the antacid pills were made of two different components, and each one would react with the acid. This action not only drew attention to a relevant aspect but also made information retained in the drawing for later use.

In brief, as entities represented in drawings did not need to be referred to in speech, they also did not have to be held in memory, thus reducing the cognitive load [18]. When talk and gestures are on the drawing, drawing provides the stable medium that adds meaning to both talk and gestures $[18,41]$. In this case, as the drawings were a joint creation emerging from an ongoing negotiation of individual's representations, the drawn entities have a shared meaning for both students. Most frequently, we found both students using talk and gestures on the drawings for conveying their ideas. In other words, they talked to each other through embodied actions on the drawing, which made their conversation highly contextual and fluent with minimal verbal resources. Together the representational function of drawing and gestures helped students to articulate more ideas in the exchange because these modalities assume what would otherwise have to be put into words during the conversation $[16,18,29]$. In turn, once the continuous flow of the turn-taking was ensured, it was easier for students to introduce their ideas into the conversation, and thereby to develop higher levels of thinking [4].

\section{Summary and Implications}

Our findings suggest that the activity of jointly creating a drawing plays a role in establishing a genuine shared-action space, a we-space. As a genuine shared-action space, a we-space is established and sustained through complex interactive processes of mutual cooperation and joint attention. It occurs when two or more individuals are mutually responsive to each other, making the necessary adjustments to achieve interpersonal understanding, resulting in the emergence of new ideas that were not previously available to the individual parts, but emerged as a shared achievement [34]. A drawing, as a visuo-spatial 
representation, requires making decisions about which objects to draw and how to draw it, for instance, regarding their shape, size, and location [29]. In addition, in particular, creating a drawing at the scalar level of particles requires deciding on entities and processes that cannot be seen [10]. In this case, students engaged in drawing creation with their individual representations and intentions. Thus, creating a joint drawing required them to make sense of each other's representations and intentions as well as to cooperate in developing a shared one. In addition, and more interesting, drawing itself enabled complex interactions that drove processes of mutual cooperation and joint attention. Our findings showed students exploiting the drawing space by gesturing and sketching, which served to enact their individual (private) representations and, thus, to make them perceptually available. This, in turn, worked to orient students' attention towards each other's intentions and move the interaction from the private space to the shared space. In this process, both students established a genuine shared-action space, a we-space, or a space of sustained focused interaction that opened possibilities for interpersonal processes of understanding [34]. These findings give strength to arguments elsewhere (e.g., [16,17,37]) that drawing cannot be reducible to a sketching activity, but it is also a social-cognitive one. Collaborative drawing may be seen as a social-cognitive space, where drawing plays a role in its establishment and management.

In this study, the we-space is a distributed system formed by the drawing, each student's internal representations, and their communicative and embodied actions in drawing. Within the we-space, the drawing's functions extended from supporting thinking to enabling collective thinking-in-action. Our findings showed students performing embodied actions on the drawing, such as gestures to simulate real-time representations. From the point of view of the theories of embodied and distributed cognition [21,25,26], these real-time representations evidence instances of collective thinking-in-action, emerging from a distributed system using representations that exist both internally and externally, which are enacted as external representations that complement and enhance internal and individual representations [22,29,34,42]. Thus, our findings support the ongoing work on embodied and distributed cognition, suggesting that the material environment and embodied action on the material environment are critical parts of the process of thinking that cannot be treated as separated but instead as a distributed system [27,29-32]. In the case of collaborative drawing, we tentatively suggest that the thinking process is not either with or without the drawing [28], instead it is enacted through the ongoing interaction of multiple modal representations, including talk, gestures, and sketch, distributed over space, time, and participants. Indeed, a main contribution of this study was to provide empirical evidence to the theoretical ideas regarding distributed cognition and its potential to promote learning as well as that drawing has an active function in these processes.

Finally, in the joint creation of a drawing, part of the communication activity was done through the drawing by embodied actions that functioned to simplify communication in various ways. We found that as drawing took form, students' conversation was conducted through the drawing. Students' talk was frequently coupled with gestures on the drawing that functioned to make the conversation more accessible, thus helping to develop shared, coherent lines of thought and follow them smoothly. Gestures have been already recognized as an essential form of embodiment in language that facilitates communication (e.g., [31-33,43,44]). However, few studies have paid attention to the development and use of gestures in collaborative drawings (e.g., [16-18]). In this study, abstract entities and their spatial relations represented in a drawing were easily brought into the conversation by pointing gestures. Rather than having a conversation about abstract entities, the students conversation was about concrete entities that could easily be brought into the conversation by efficient gestures on the drawing, avoiding cumbersome language and allowing for establishment and maintenance of common ground. These findings are in line with the view that gestures convey spatial information, since they help $\mathrm{d}$ to organize spatial information for speech and, thus, to conceptualize the information to convey $[17,41,43,44]$. 
In conclusion, the general argument that we sought to support through the present study is that drawing, as a joint activity, has potentialities for learning that are not restricted to the cognitive process related to the activity of creating external visual representations on paper; rather, the benefits of drawing lie in action in space. Creating these representations is more than a process of externalization of thought; it is part of a process of collective thinking-in-action.

One important note: in this study, the drawing activity was sufficiently open to allow students' creativity and imagination while actively creating their own products. The fact that students jointly created a drawing with minimal guidance to explain a phenomenon that deals with the unobservable level of atoms and molecules left space for interpretation of individual intentions and negotiation. These findings give strength to arguments elsewhere that it is not the drawing itself, but how drawings are used, that best supports learning [8]. While we believe that our work supports the argument to incorporate drawing activities into the science classroom, we are also aware that drawing, like many other classroom activities, is tightly related to the nature of the task in which students engage. In fact, researchers in science education claim that drawing may not always provide the expected benefits for students learning unless it is purposefully integrated into practices that challenge students to use their drawings to think $[3,45]$. Hence, the dimension of joint-drawing creation as a sufficiently open-ended task is a critical issue to incorporate in instructional practice.

This study did not occur without limitations. We analyzed a single case study that did not occur in a classroom setting, since our purpose was to conduct a fine-grained analysis that would allow us to describe a mechanism in great detail. The students' interaction was undoubtedly influenced by this particular social-cultural context. We believe that further research, to account for the role of drawing within other educational settings, such as the classroom, will be needed to expand our knowledge. Nevertheless, this article makes an important contribution because the framework and analysis presented here can provide the basis for such lines of research. From the many possibilities for collaborative drawing to learn, we advocated for the potential usage of drawing to understand and explain phenomena that requires dealing with lower-scalar-levels, with entities that cannot can be depicted by sketching their structures and spatial relations, which can then be used to simulate their behaviors by embodied actions. Such drawing activities have the potential to turn an abstract problem into a perceptual-action experience.

This study also has implications for research by strengthening the argument for the importance of multimodal analytical approaches. We have illustrated how a multimodal analysis produced a rich description of the social and cognitive process, when students jointly created and used a drawing, and how the drawing in this environment shaped these processes. The multimodal analytical approach helped to focus on drawing and the interrelationship between the verbal and other modes of interactions concomitantly occurring. Hence, we argue that extending the current understanding of how students use drawing to learn requires an analysis of drawing within the environment of its creation and use.

Author Contributions: Conceptualization, V.D.A.; methodology, V.D.A.; validation, S.F. and Y.S.; formal analysis, V.D.A.; Funding acquisition, V.D.A.; investigation, V.D.A., S.F. and M.B.; resources, V.D.A.; writing — original draft preparation, V.D.A.; writing — review and editing, V.D.A. and S.F. All authors have read and agreed to the published version of the manuscript.

Funding: Research funded by Fundação para a Ciência e Tecnologia (SFRH/BD/119701/2016).

Institutional Review Board Statement: Comissão de Ética do Instituto de Educação da Universidade de Lisboa (Ethical Committee of Instituto of Education of the University of Lisbon). Approval Code: 4382. Approval Date: 10 December 2021.

Informed Consent Statement: Informed consent was obtained from all subjects involved in the study.

Data Availability Statement: Data are available if required.

Acknowledgments: The authors are grateful to the students who volunteer to participate in this study. 
Conflicts of Interest: The authors declare no conflict of interest. The funders had no role in the study's design, in the collection, analyses, or interpretation of data, in the writing of the manuscript, or in the decision to publish the results.

\section{References}

1. Lynch, M.; Woolgar, S. Representation in Scientific Practice; MIT Press: Cambridge, MA, USA, 1990.

2. Ainsworth, S.; Prain, V.; Tytler, R. Drawing to learn in science. Science 2011, 333, 1096-1097. [CrossRef] [PubMed]

3. Chi, M.T.H.; Wylie, R. The ICAP Framework: Linking Cognitive Engagement to Active Learning Outcomes. Educ. Psychol. 2014, 49, 219-243. [CrossRef]

4. Forbus, K.D.; Ainsworth, S. Editors' Introduction: Sketching and Cognition. Top. Cogn. Sci. 2017, 9, 864-865. [CrossRef] [PubMed]

5. Akaygun, S. Is the oxygen atom static or dynamic? The effect of generating animations on students' mental models of atomic structure. Chem. Educ. Res. Pract. 2016, 17, 788-807. [CrossRef]

6. De Andrade, V.; Freire, S.; Baptista, M. Constructing Scientific Explanations for Chemical Phenomena through Drawings among 8th-grade Students. EURASIA J. Math. Sci. Tech. Educ. 2021, 17, 1305-8223. [CrossRef]

7. Cooper, M.M.; Stieff, M.; DeSutter, D. Sketching the invisible to predict the visible: From drawing to modelling in chemistry. Top. Cogn. Sci. 2017, 9, 902-920. [CrossRef] [PubMed]

8. Brooks, M. Drawing, Visualisation and Young Children's Exploration of "Big Ideas". Int. J. Sci. Educ. 2009, 31, 319-341. [CrossRef]

9. Schwarz, C.V.; Reiser, B.J.; Davis, E.A.; Kenyon, L.; Achér, A.; Fortus, D. Developing a learning progression for scientific modeing: Making scientific modeling accessible and meaningful for learners. J. Res. Sci. Teach. 2009, 46, 632-654. [CrossRef]

10. Parnafes, O. Developing Explanations and Developing Understanding: Students Explain the Phases of the Moon Using Visual Representations. Cogn. Instr. 2012, 30, 359-403. [CrossRef]

11. Tytler, R.; Prain, V.; Aranda, G.; Ferguson, J.; Gorur, R. Drawing to reason and learn in science. J. Res. Sci. Teach. 2020, 57, 209-231. [CrossRef]

12. Tippett, $\mathrm{C}$. What recent research on diagrams suggests about learning with rather than learning from visual representations in science. Int. J. Sci. Educ. 2016, 38, 725-746. [CrossRef]

13. Cabello, V.M.; Moreira, P.M.; Griñó Morales, P. Elementary Students' Reasoning in Drawn Explanations Based on a Scientific Theory. Educ. Sci. 2021, 11, 581. [CrossRef]

14. Wilkerson-Jerde, M.H.; Gravel, B.E.; Macrander, C.A. Exploring Shifts in Middle School Learners' Modeling Activity While Generating Drawings, Animations, and Computational Simulations of Molecular Diffusion. J. Sci. Educ. Technol. 2015, 24, 396-415. [CrossRef]

15. Park, J.; Tang, K.-S.; Chang, J. Plan-Draw-Evaluate (PDE) pattern in students' collaborative drawing: Interaction between visual and verbal modes of representation. Sci. Educ. 2021, 1, 21668. [CrossRef]

16. Tholander, J.; Karlgren, K.; Ramberg, R.; Sökjer, P. Where All the Interaction Is Sketching in Interaction Design as an Embodied Practice. In Proceedings of the 7th ACM Conference on Designing Interactive Systems, Cape Town, South Africa, 25 February 2008; pp. 445-454. [CrossRef]

17. Wardak, D. Encapsulating Concepts in Gestures and Drawings during Educational Design Team Meetings. Mind Cult. Act. 2017, 24, 47-66. [CrossRef]

18. Osbeck, L.M.; Nersessian, N.J. Situating distributed cognition. Philos. Psychol. 2014, 27, 82-97. [CrossRef]

19. Hutchins, E. The cultural ecosystem of human cognition. Philos. Psychol. 2014, 27, 34-49. [CrossRef]

20. Hutchins, E. The distributed cognition perspective on human interaction. In Roots of Human Sociality: Culture, Cognition and Interaction; Enfield, N.J., Levinson, S.C., Eds.; Berg: Oxford, UK, 2006; pp. 375-398.

21. Osbeck, L.M.; Nersessian, N.J. The Distribution of Representation. J. Theory Soc. Behav. 2006, 36, 0021-8308. [CrossRef]

22. Hutchins, E. How a cockpit remembers its speeds. Cogn. Sci. 1995, 19, 265-288. [CrossRef]

23. Nersessian, N.J. The Cognitive-Cultural Systems of the Research Laboratory. Organ. Stud. 2006, 27, 125-145. [CrossRef]

24. Barsalou, L.W. Grounded cognition. Annu. Rev. Psychol. 2008, 59, 617-645. [CrossRef] [PubMed]

25. Wilson, M. Six views of embodied cognition. Psychon. Bull. Rev. 2002, 9, 625-636. [CrossRef] [PubMed]

26. Abrahamson, D. Embodied design: Constructing means for constructing meaning. Educ. Stud. Math. 2009, 70, 27-47. [CrossRef]

27. Abrahamson, D.; Lindgren, R. Embodiment and Embodied Design. In The Cambridge Handbook of the Learning Sciences: Part III-Practices that Foster Effective Learning; Sawyer, R.K., Ed.; Cambridge University Press: Cambridge, UK, 2014 ; pp. 358-376. [CrossRef]

28. Goldin-Meadow, S.; Beilock, S.L. Action's Influence on Thought: The Case of Gesture. Perspect. Psychol. Sci. 2010, 5, 664-674. [CrossRef] [PubMed]

29. Langbeheim, E.; Levy, S.T. Feeling the forces within materials: Bringing inter-molecular bonding to the fore using embodied modelling. Int. J. Sci. Educ. 2018, 40, 1567-1586. [CrossRef]

30. Alibali, M.W.; Nathan, M.J. Embodiment in Mathematics Teaching and Learning: Evidence From Learners' and Teachers' Gestures. J. Learn. Sci. 2012, 21, 247-286. [CrossRef]

31. DeLiema, D.; Enyedy, N.; Steen, F.; Joshua, A.; Danish, J.A. Integrating Viewpoint and Space: How Lamination across Gesture, Body Movement, Language, and Material Resources Shapes Learning. Cogn. Instr. 2021, 39, 328-365. [CrossRef] 
32. Mathayas, N.; Brown, D.E.; Wallon, R.C.; Lindgren, R. Representational gesturing as an epistemic tool for the development of mechanistic explanatory models. Sci. Educ. 2019, 103, 1047-1079. [CrossRef]

33. Zhang, J. The nature of external representations in problem solving. Cogn. Sci. 2009, 21, 179-217. [CrossRef]

34. Krueger, J. Extended cognition and the space of social interaction. Conscious. Cogn. 2011, 20, 643-657. [CrossRef]

35. Theiner, G.; Allen, C.; Goldstone, R.L. Recognizing group cognition. Cogn. Syst. Res. 2010, 11, 378-395. [CrossRef]

36. Varga, S.; Krueger, J. Background emotions, proximity, and distributed emotion regulation. Rev. Philos. Psychol. 2013, 4, 271-292. [CrossRef]

37. Tversky, B.; Suwa, M. Thinking with sketches. In Tools for Innovation: The Science Beyond the Practical Methods that Drive New Ideas; Markman, A.B., Wood, K.L., Eds.; Oxford University Press: New York, NY, USA, 2009; pp. 75-84.

38. Bezemer, J.; Jewitt, C. Multimodal analysis: Key issues. In Research Methods in Linguistics; Litosseliti, L., Ed.; Continuum Books: London, UK; New York, NY, USA, 2009; pp. 180-197.

39. Twiner, A.; Littleton, K.; Whitelock, D.; Coffin, C. Combining sociocultural discourse analysis and multimodal analysis to explore teachers' and pupils' meaning making. Learn. Cult. Soc. Interact. 2021, 30, 100520. [CrossRef]

40. Bryan-Kinns, N.; Healey, P.G.T.; Leach, J. Exploring Mutual Engagement in Creative Collaborations. In Proceedings of the 6th ACM SIGCHI Conference on Creativity \& Cognition, Washington, DC, USA, 13-15 June 2007; pp. 223-232. [CrossRef]

41. Heiser, J.; Tversky, B.; Silverman, M. Sketches for and from collaboration. In Visual and Spatial Reasoning in Design III; Gero, J.S., Tversky, B., Knight, T., Eds.; Key Centre for Design Research: Sydney, Australia, 2004; pp. 69-78.

42. Krueger, J. Seeing mind in action. Phenomenol. Cogn. Sci. 2012, 11, 149-173. [CrossRef]

43. Alibali, M.W. Gesture in Spatial Cognition: Expressing, Communicating, and Thinking About Spatial Information. Spat. Cogn. Comput. 2005, 5, 307-331. [CrossRef]

44. Kang, S.; Tversky, B. From hands to minds: Gestures promote understanding. Cogn. Res. Princ. Implic. 2016, 1, 4. [CrossRef]

45. Kelly, R.M.; Jones, L.L. Investigating Students' Ability to Transfer Ideas Learned from Molecular Animations of the Dissolution Process. J. Chem. Educ. 2008, 85, 303-309. [CrossRef] 